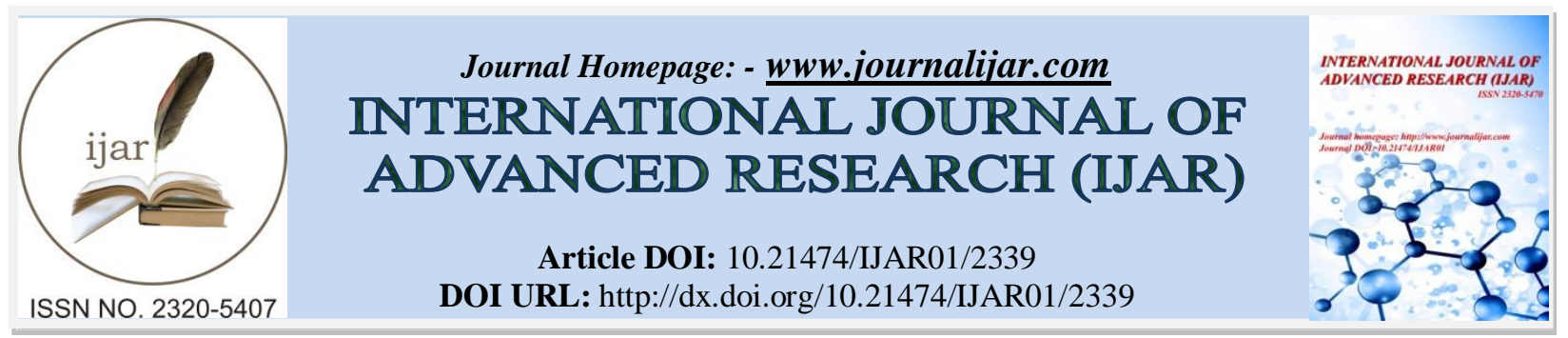

RESEARCH ARTICLE

\title{
IN VITRO SHOOT MULTIPLICATION OF STEVIA REBAUDIANA (BERT) THROUGH PLANT TISSUE CULTURE.
}

*Vibha Bhingradiya ${ }^{1}$, Archana Mankad², Ruby Patel ${ }^{3}$ and Shivangi Mathur ${ }^{3}$.

1. Department of Botany, University School of Science., Gujarat University, Ahmedabad (Gujarat) India

2. Professor and Head of the Botany Department, Uni. School Of Science, Gujarat University, Ahmedabad (Gujarat) India

3. Assistant professor in President Science College, Gujarat University, Ahmedabad (Gujarat) India

\section{Manuscript Info}

(.........................

Manuscript History

Received: 30 September 2016

Final Accepted: 30 October 2016

Published: November 2016

Key words:-

Stevia rebaudiana (Bert), Cytokinin, Auxin, Callus, Shoot Multiplication, MR (Multiplication Rate).

\section{Abstract}

Stevioside obtained from the leaves of Stevia rebaudiana (Bert) is regarded as a valuable natural sweetening agent because of its relatively good taste and chemical stability. But Seed germination of the plant is poor. Due to low viability of seeds, present experiment attempts to study the effect of various basal salts and phytohormones on various aspects of shoot multiplication through in vitro technique. Various concentrations and combinations of BAP and NAA were used in MS medium and WPM medium and observed for the morphogenic responses of explants of Stevia rebaudiana (Bert). During the experiments it was observed that combination of WPM was the best performer in comparison with MS medium. It gave better growth in terms of number of shoots, length of shoots, number of internodes, multiplication rate and callus induction.

Copy Right, IJAR, 2016,. All rights reserved.

:-

Stevia rebaudiana (Bert) is an herbaceous perennial plant belonging to Asteraceae family. It is a natural non caloric sweet tasting plant used around the world for its intense sweet taste. Diterpene glycosides produced by Stevia rebaudiana (Bert) leaves are many times sweeter than sucrose. They can be utilized as a substitute of sucrose ${ }^{1,2,3,4,5,6}$. The potential uses of Stevia rebaudiana (Bert), is to produce stevioside, a non-caloric sweetener that does not metabolize in the human body. The sweet compounds pass through the digestive process without chemically breaking down, making Stevia safe for those who need to control their blood sugar level ${ }^{7}$. Stevia rebaudiana (Bert) is non-toxic, non-caloric, non-plaque, non-fermentative, flavor enhancing, non-carcinogenic, and has non-addictive sweetness. Stevioside and rebaudioside induce insulin secretion and the former acts as anti-tumor agent ${ }^{8}$.

The seeds of Stevia show a very low germination percentage. Propagation by seeds does not allow the production of homogeneous populations, resulting in great variability in important features like sweetening levels and composition ${ }^{9}$. Vegetative propagation too is limited by the lower number of individuals that can be obtained simultaneously from a single plant ${ }^{10}$. Due to the above-mentioned difficulties, tissue culture is the only alternative for rapid multiplication of Stevia rebaudiana (Bert), plants. The multiplication of Stevia rebaudiana (Bert) takes place most commonly by shoot tip culture and by stem cutting.

Corresponding Author:- Vibha Bhingradiya.

Address:- Department of Botany, University School of Science., Gujarat University, Ahmedabad (Gujarat) India. 
The present study was aimed to understand the effect of different plant growth regulators at various concentrations on in vitro shoot induction and indirect plant regeneration of Stevia rebaudiana (Brert). During process of micropropagation all types visible infections are rejected to maintain aseptic culture condition. The resultant micropropagated plants are disease free and healthy.

\section{Material and Method:- \\ Plant Collection:-}

$1 \mathrm{~cm}$ length of shoot tip segments of Stevia rebaudiana (Bert) collected from the established in vitro shoot cultures at Tissue culture Labortory, Cadilla Pharmaceutical limited, Ahmedabad, were used for experiments.

\section{Culture Medium:-}

Separate stock solutions were prepared according to the composition of the medium and were stored at $7-8{ }^{\circ} \mathrm{C}$ temp. The $\mathrm{pH}$ of the media was adjusted to $5.8 \pm 0.1$ using $0.1 \mathrm{~N} \mathrm{NaOH}$ or $0.1 \mathrm{~N} \mathrm{HCL}$. Various concentration of Cytokinin (BAP) in combinations with Auxin (NAA) and alone i.e. $\mathrm{T}_{1}(\mathrm{BAP} 0.0 \mathrm{mg} / \mathrm{l}, \mathrm{NAA} 0.0 \mathrm{mg} / \mathrm{l}), \mathrm{T}_{2}$ (BAP $0.05 \mathrm{mg} / \mathrm{l}, \mathrm{NAA} 0.0 \mathrm{mg} / \mathrm{l}$ ), $\mathrm{T}_{3}$ (BAP $0.10 \mathrm{mg} / \mathrm{l}$, NAA $0.0 \mathrm{mg} / \mathrm{l}$ ), $\mathrm{T}_{4}$ (BAP $0.0 \mathrm{mg} / \mathrm{l}, \mathrm{NAA} 0.05 \mathrm{mg} / \mathrm{l}$ ), $\mathrm{T}_{5}$ (BAP 0.05 $\mathrm{mg} / \mathrm{l}$, NAA $0.05 \mathrm{mg} / \mathrm{l}$ ), $\mathrm{T}_{6}$ (BAP $0.10 \mathrm{mg} / \mathrm{l}$, NAA $0.05 \mathrm{mg} / \mathrm{l}$ ), $\mathrm{T}_{7}$ (BAP $0.0 \mathrm{mg} / \mathrm{l}, \mathrm{NAA} 0.10 \mathrm{mg} / \mathrm{l}$ ), $\mathrm{T}_{8}$ (BAP 0.05 $\mathrm{mg} / \mathrm{l}$, NAA $0.10 \mathrm{mg} / \mathrm{l}$ ), $\mathrm{T}_{9}$ (BAP $0.10 \mathrm{mg} / \mathrm{l}$, NAA $0.10 \mathrm{mg} / \mathrm{l}$ )were incorporated in MS and WPM medium along with $3 \%$ sucrose and $0.7 \%$ agar and then observations were recorded.

\section{Culture Condition:-}

All the cultures were incubated under in growth room with $16 \mathrm{hr}$ photoperiod of light having $65.33 \mu \mathrm{molm}^{-2} . \mathrm{S}^{-2}$ intensity (1500 flux). Temperature of growth room was maintained at $26 \pm 2{ }^{\circ} \mathrm{C}$ with $55-60 \%$ relative humidity.

\section{Results and Discussion:-}

In the present experiment, attempts were made to study the effect of various basal salts and phytohormones on various aspects of shoot multiplication in Stevia rebaudiana (Bert). Various concentration and combination of BAP and NAA were used in MS medium and WPM medium, and observed for the morphogenic responses of explants of Stevia rebaudiana (Bert).

After 30 days of inoculation, the highest number of shoot induction and highest length of shoot was observed in Treatment $\mathrm{T}_{5}(5.83)$ and Treatment $\mathrm{T}_{6}(2.52 \mathrm{~cm})$ in MS basal media and The lowest average number of shoot induction and lowest length of shoot was found in Treatment $\mathrm{T}_{4}(0.48)$ and Treatment $\mathrm{T}_{4}(0.77)$ in MS basal media. While in WPM basal medium the highest number of shoot induction and highest length of shoot was observed in Treatment $T_{3}(15.8)$ and Treatment $T_{8}(5.79 \mathrm{~cm})$ and The lowest average number of shoot induction and lowest length of shoot was found in Treatment $\mathrm{T}_{4}(0.99)$ and Treatment $\mathrm{T}_{6}(3.08 \mathrm{~cm})$. This result indicates that the high level of Cytokinin alone gives best number of shoots as compared to combination with Auxin and absence of Cytokinin in medium decreased the length of shoot. Same result shows that high level of Cytokinin proved best for the shoot induction and shoot length as compared to combination with Auxin in this plant which is supported by ${ }^{11}$. He reported that the highest Numbers of Shoots produced on medium supplemented with BAP alone were best then other media.

In MS basal media, the number of internodes was highest in Treatment $T_{5}(2.28)$ the lowest number of internodes was obtained in Treatment $\mathrm{T}_{4}(0.60)$, while in WPM basal the highest number of internodes were observed in Treatment $T_{7}$ (4.28) and the lowest number of internodes was obtained in Treatment $T_{2}$ (2.49). This indicates that absence of Cytokinin in medium decrease the number of internodes in MS medium while the absence of Cytokinine increases number of internodes in WPM medium. High level of Cytokinin and lower level of NAA combination is proved best for more growth of internodes as compared to Auxin alone. Similar results were reported by ${ }^{12}$.

Higher level of Cytokinin proved its ability to induce more shoots which was observed during the experiment. Lower level or absence of Cytokinin resulted into lower multiplication rate or inhibit the multiplication respectively. During experiment it was observed that the highest multiplication rate was observed in Treatment $T_{6}(3.17)$ whereas the lowest multiplication rate was observed in Treatment $\mathrm{T}_{7}(0.32)$ with MS basal and the highest multiplication rate was observed in Treatment $T_{3}(11.7)$, whereas the lowest multiplication rate was observed in Treatment $T_{4}(2)$ with WPM basal medium. (Figure-2). 
Though BAP at its high level induces more multiplication rate, it also induces the callus indicating imbalance of Auxin -Cytokinin ratio with basal medium ${ }^{13}$ reported rapid and reproducible regeneration in vitro protocol with BA for Stevia rebaudiana (Bert) via nodal shoot multiplication. Similar observation was also reported by ${ }^{13}$.

Table 1:- Different Combination of Phytohormones (BAP and NAA) used with MS and WPM basal medium.

\begin{tabular}{|c|c|c|c|c|}
\hline \multirow{2}{*}{$\begin{array}{l}\text { Auxin } \\
\text { (mg/l) }\end{array}$} & \multicolumn{4}{|c|}{ Cytokinin (mg/l) } \\
\hline & $Y^{\prime}$ & & & \\
\hline & NAA & $0.0(\mathrm{mg} / \mathrm{l})$ & 0.05 (mg/l) & $0.10(\mathrm{mg} / \mathrm{l})$ \\
\hline & 0.0 (mg/l) & $\mathrm{T}_{1}$ & $\mathrm{~T}_{2}$ & $\mathrm{~T}_{3}$ \\
\hline & 0.05 (mg/l) & $\mathrm{T}_{4}$ & $\mathrm{~T}_{5}$ & $\mathrm{~T}_{6}$ \\
\hline & $0.10(\mathrm{mg} / \mathrm{l})$ & $\mathrm{T}_{7}$ & $\mathrm{~T}_{8}$ & $\mathrm{~T}_{9}$ \\
\hline
\end{tabular}

Table 2:- Data on Different Parameters under Study (Full MS basal Salts).

\begin{tabular}{|c|c|c|c|c|c|c|}
\hline $\begin{array}{c}\text { Treatment } \\
\text { No. }\end{array}$ & \multicolumn{2}{|l|}{ Growth hormone (mg/) } & \multicolumn{4}{|c|}{ Characters } \\
\cline { 2 - 7 } & BAP & NAA & $\begin{array}{c}\text { Avg. No. of } \\
\text { Shoots }\end{array}$ & $\begin{array}{c}\text { Length of } \\
\text { shoot (cm) }\end{array}$ & $\begin{array}{c}\text { No. of } \\
\text { Internodes }\end{array}$ & MR* \\
\hline 1 & - & - & 1.06 & 1.28 & 1.50 & 0.83 \\
\hline 2 & 0.5 & - & 4.38 & 1.43 & 1.89 & 2.11 \\
\hline 3 & 1.0 & - & 3.83 & 1.63 & 1.71 & 1.89 \\
\hline 4 & - & 0.05 & 0.48 & 0.77 & 0.60 & 0.44 \\
\hline 5 & 0.5 & 0.05 & 5.83 & 1.83 & 2.28 & 2.89 \\
\hline 6 & 1.0 & 0.05 & 5.55 & 2.52 & 2.22 & 3.17 \\
\hline 7 & - & 0.10 & 0.65 & 1.05 & 1.11 & 0.32 \\
\hline 8 & 0.5 & 0.10 & 4.44 & 1.30 & 1.43 & 2.22 \\
\hline 9 & 1.0 & 0.10 & 2.72 & 0.92 & 0.88 & 1.50 \\
\hline
\end{tabular}

Table 3:- Data on Different Parameters under Study (WPM Basal Salts).

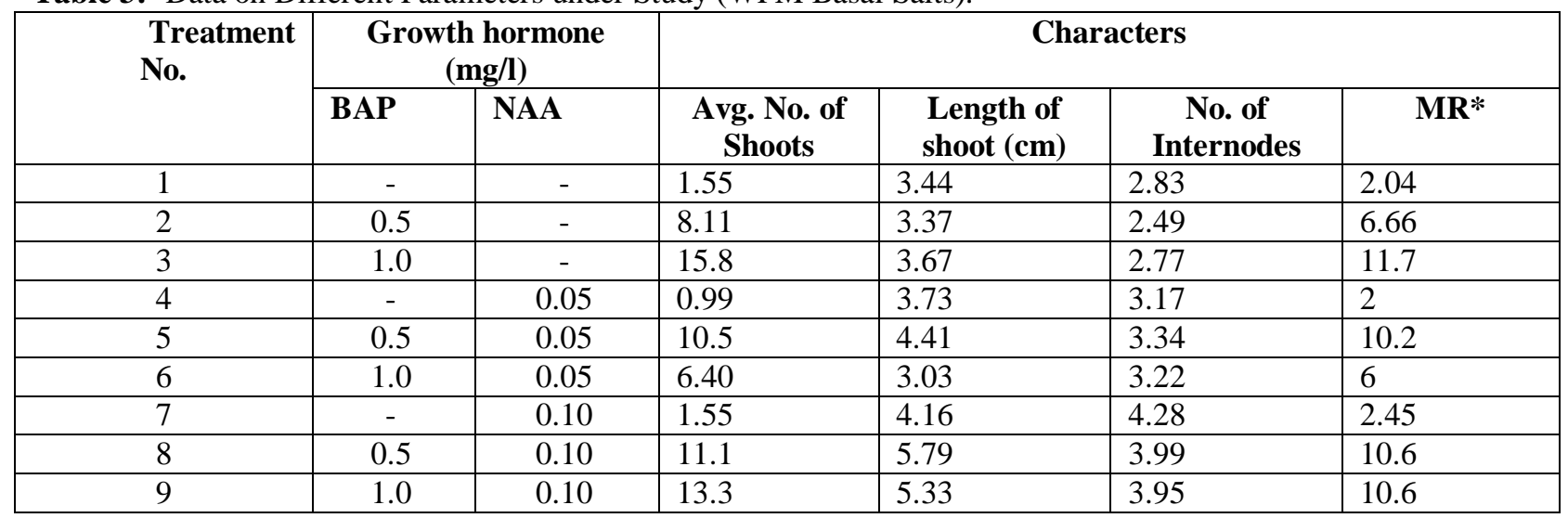

*Multiplication rate 
Figure 1:- In Vitro Growth In MS Media Supplemented With Cytokinin and Auxin.

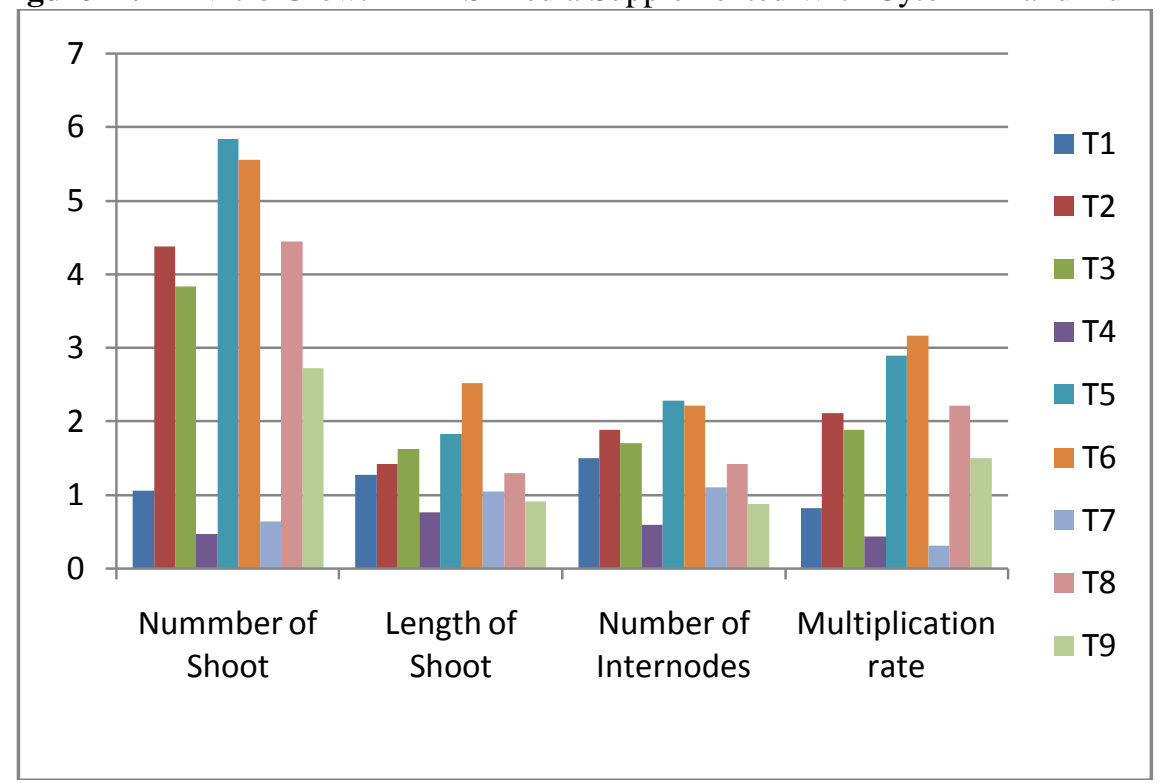

Figure 2:- In Vitro Growth in WPM Media Supplemented With Cytokinin and Auxin.

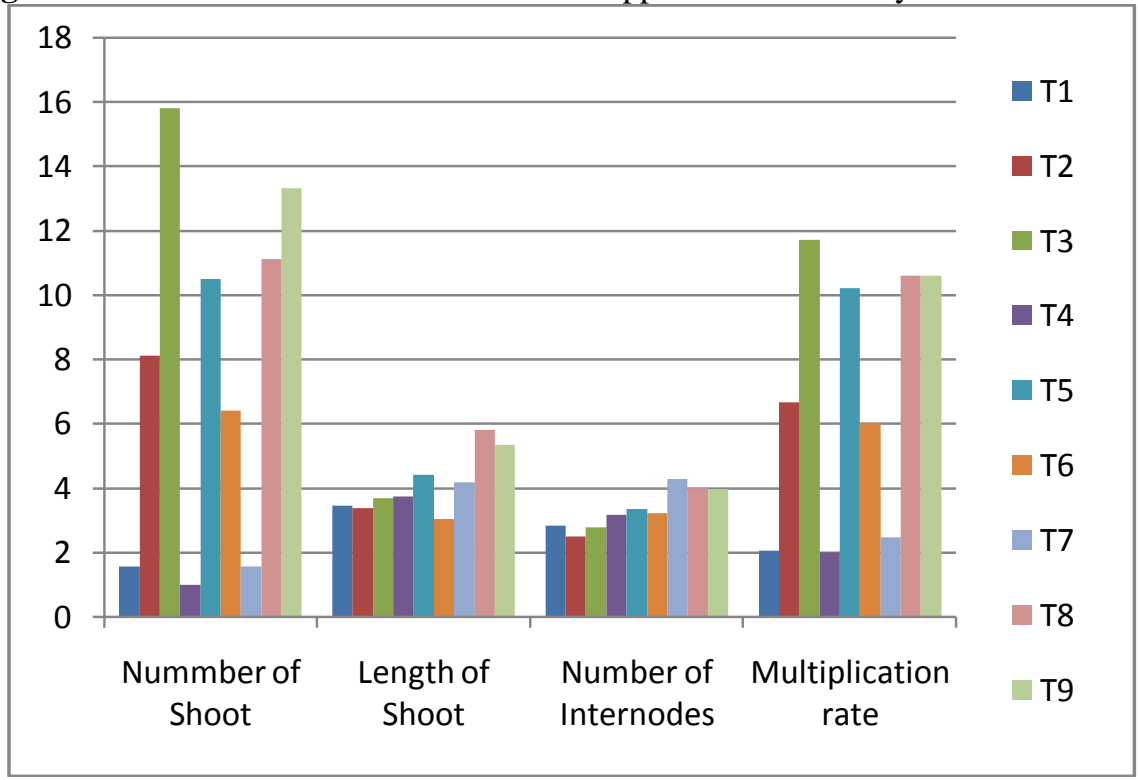


Plate 1:- (a) - Effect of Full MS medium after 30 Days of Inoculation. $\left(\mathrm{T}_{1}, \mathrm{~T}_{4}\right.$ and $\left.\mathrm{T}_{7}\right)$.
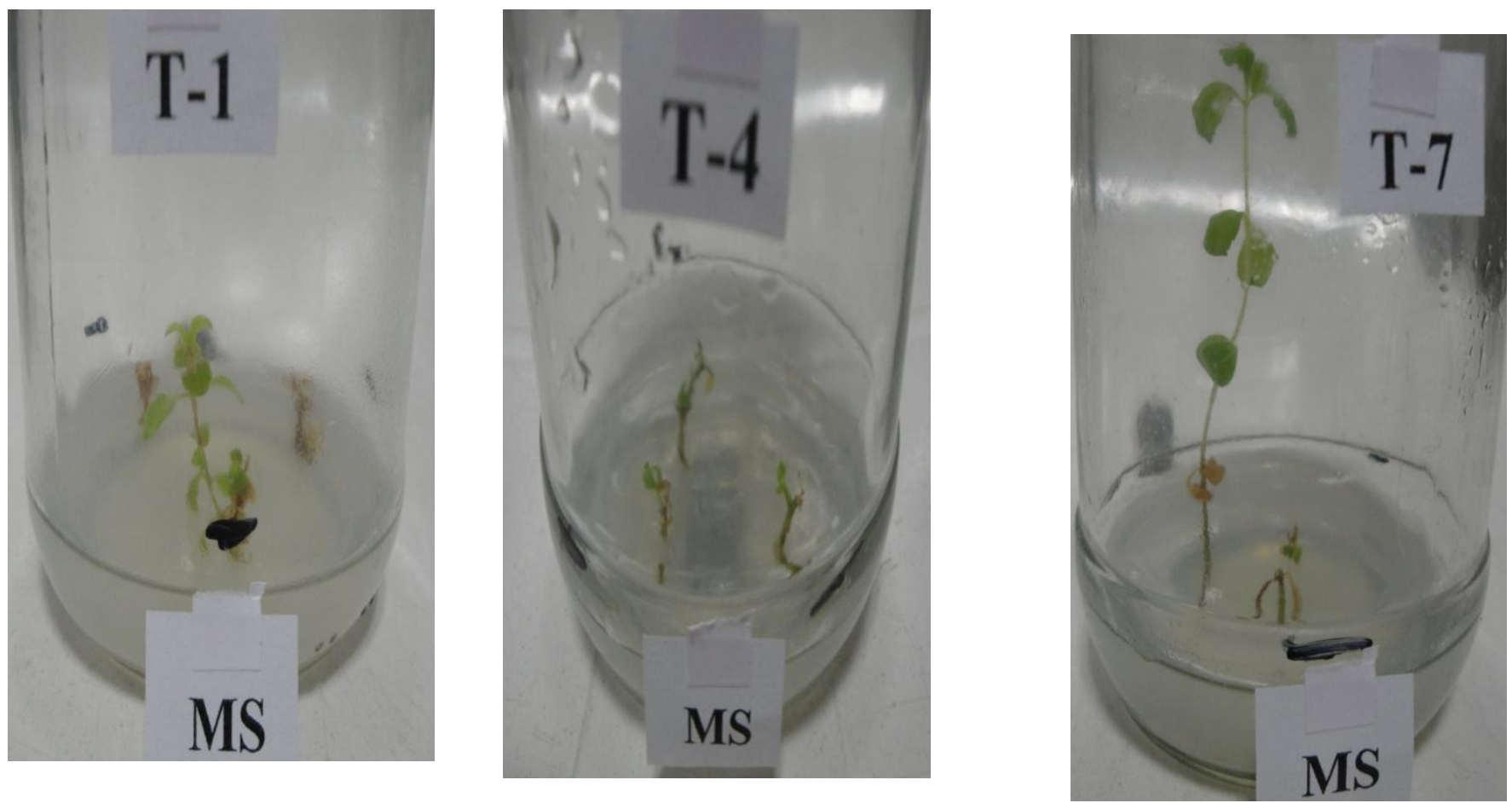

Plate 1:- (b) - Effect of Full MS medium after 30 Days of inoculation. $\left(T_{2}, T_{5}\right.$ and $\left.T_{8}\right)$.
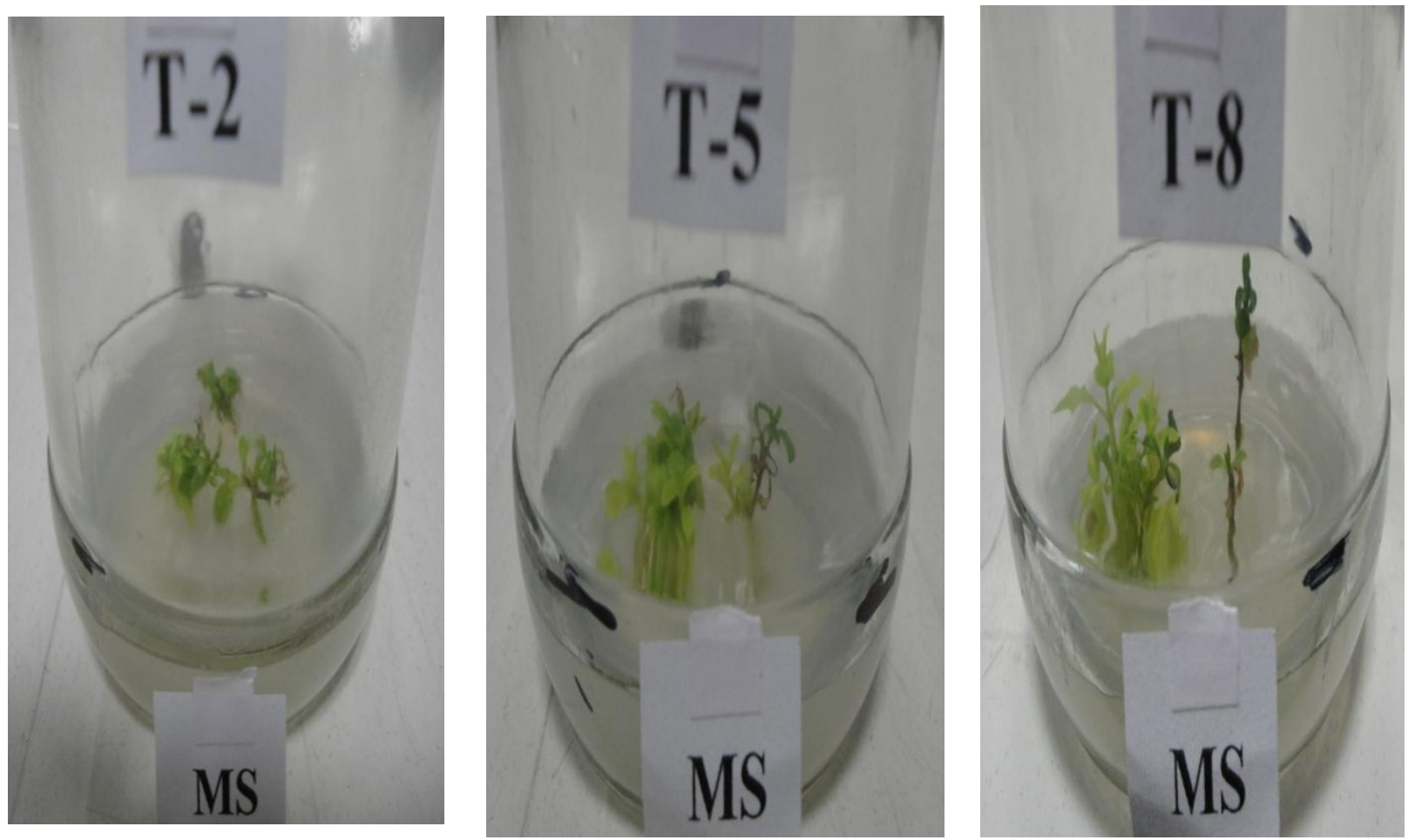
Plate 1:- (c) - Effect of Full MS medium after 30 Days of inoculation. $\left(T_{3}, T_{6}\right.$ and $\left.T_{9}\right)$.
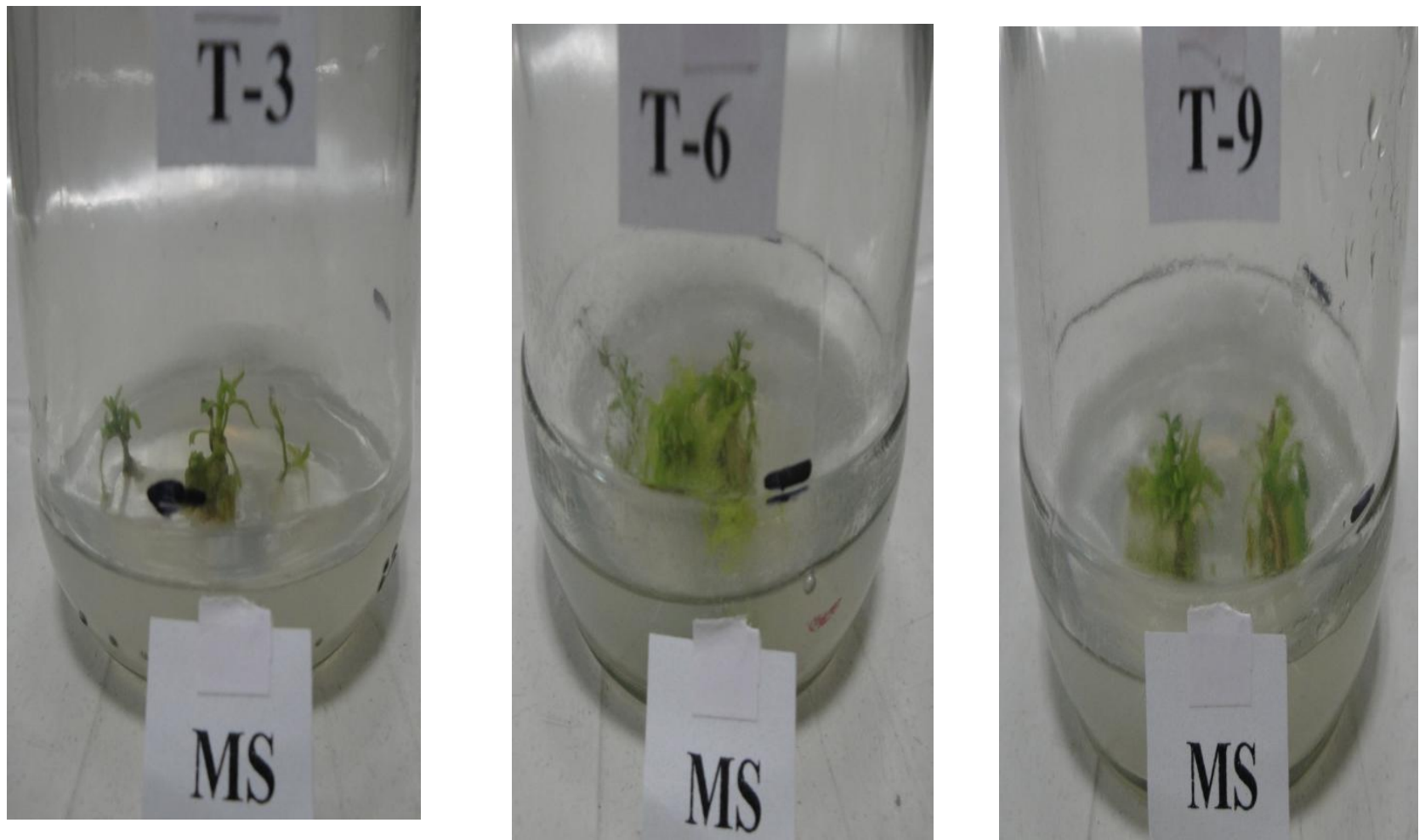

Plate 2:- (a) - Effect of WPM medium after 30 Days of inoculation. $\left(\mathrm{T}_{1}, \mathrm{~T}_{4}\right.$ and $\left.\mathrm{T}_{7}\right)$.
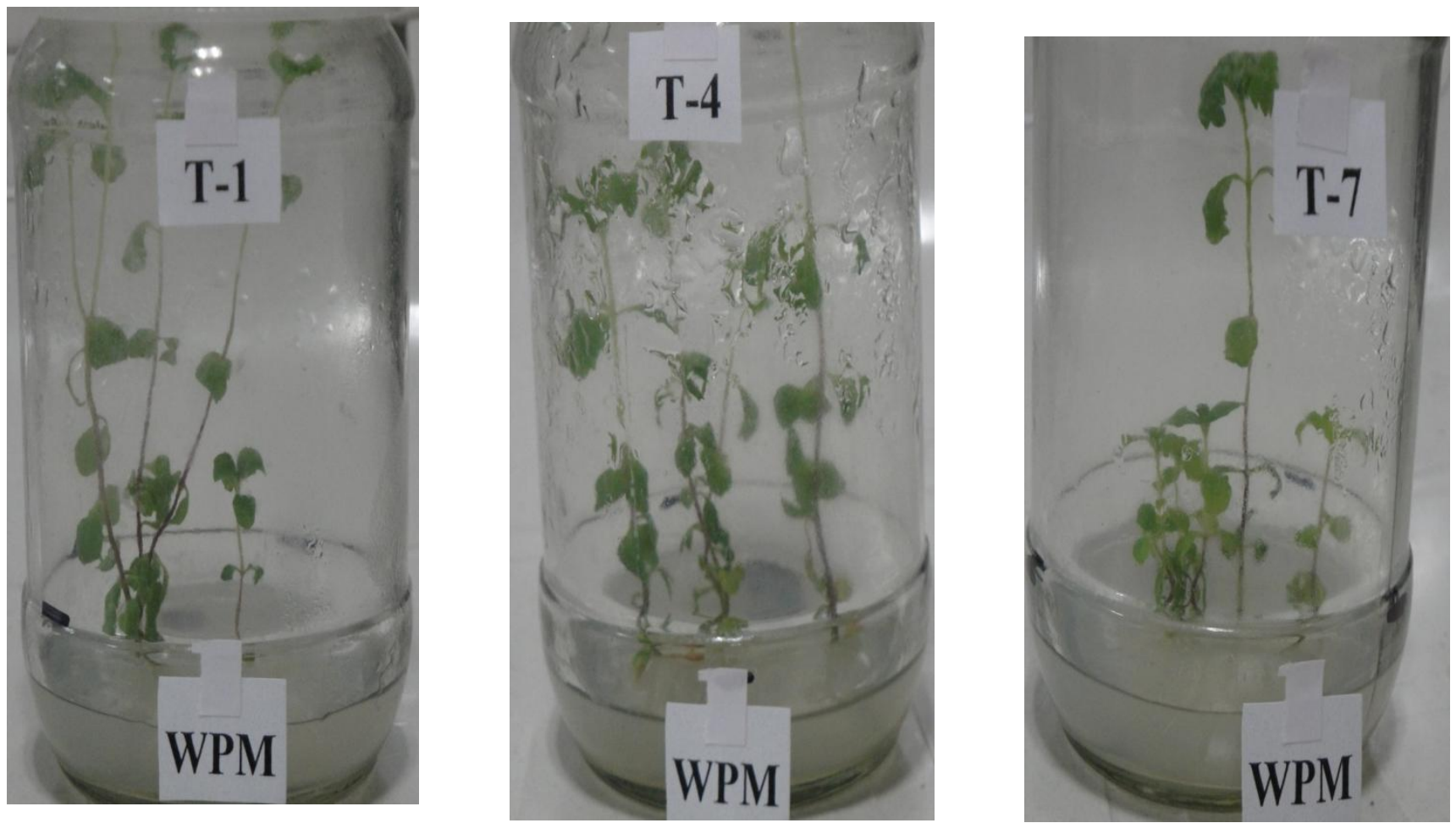
Plate 2:- (b) - Effect of WPM medium after 30 Days of inoculation. $\left(T_{2}, T_{5}\right.$ and $\left.T_{8}\right)$.
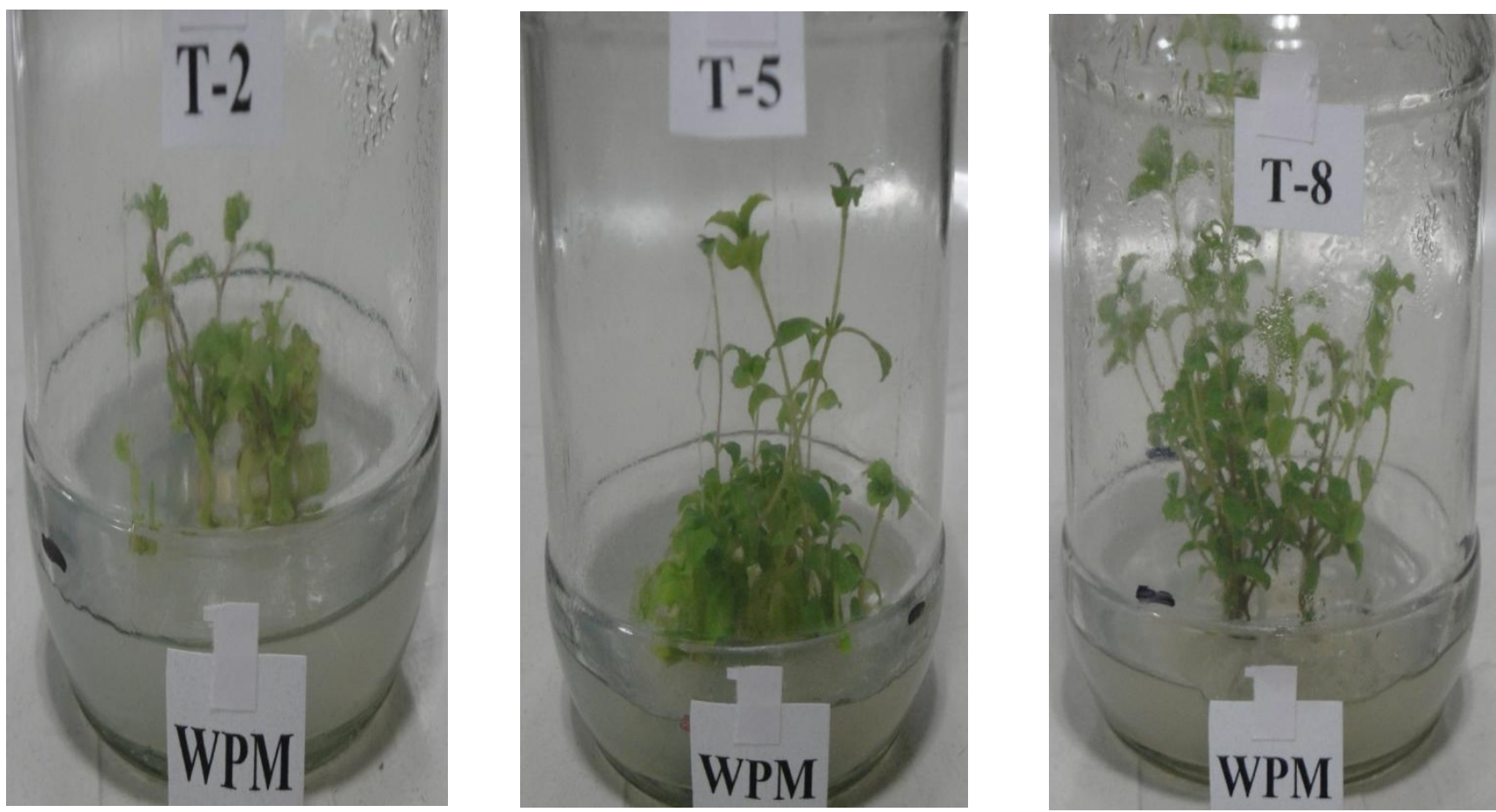

Plate 2:- (c) - Effect of WPM medium after 30 Days of inoculation. $\left(T_{3}, T_{6}\right.$ and $\left.T_{9}\right)$.
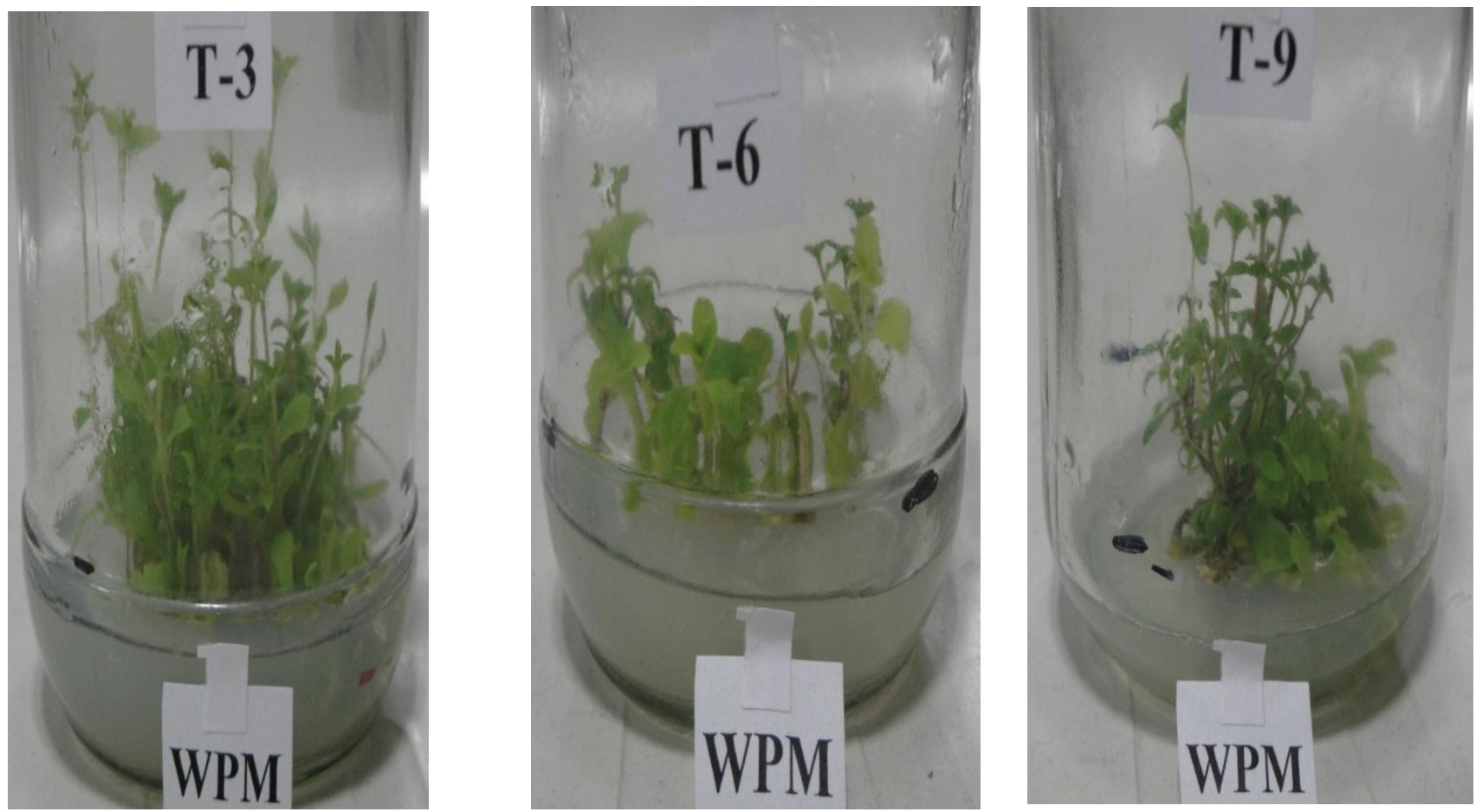


\section{Conclusion:-}

Role of Cytokinin and Auxin in shoot multiplication during in vitro culture was proved by many workers ${ }^{14,15,16,17}$. In case of Stevia rebaudiana (Bert), present study proved that ratio of NAA 1.1 and BAP 1:2 gave best growth in WPM media in number of shoots, length of shoot, number of internodes, multiplication rate as compare to MS medium.

\section{Acknowledgement:-}

Authors Vibha B, Archana M, Ruby P, Shivangi M would like to express their gratitude to Gujarat University for continuous support through Dissertation work. We would also like to thank all Professors and Head of the department of Botany, Gujarat University (Ahmedabad) for providing working and instrumental facilities and support. We extend our sincere thanks to management of President Science College for providing support.

\section{References:-}

1. Robinson R L, (1930) Contributions from the Gray Herbarium of Harvard University XC, The Gray Herbarium of Harvard University, Cambridge, MA, 78-91.

2. Soejarto D D, Kinghorn A D, \& Farnsworth N R, (1982) Potential sweetening agents of plant origin III, Organoleptic evaluation of Stevia leaf herbarium samples for sweetness, Journal of natural products, 45(5) 590-599.

3. Soejarto, D. D,, Compadre, C. M., Medon, P. J., Kamath, S. K., Kinghorn, A. D. (1983): Potential sweetening agents of plant origin II, Field search for sweet-tasting Stevia species, Economic Botany, 37(1) 71-79.

4. Yadav, A. K., Singh, S., Dhyani, D., and Ahuja, P. S. (2011): A review on the improvement of Stevia (Stevia rebaudiana (Bertoni), Canadian Journal of Plant Science, 91(1) 1-27.

5. Matsui, K., Kawasaki, Y., Oda, Y., Noguchi, T., Kitagaewa, Y., Sawada, M. (1996): Evaluation of the genotoxicity of stevioside and steviol using six in vitro and one in vivo mutagenicity assays, Mutagenesis, 11 573-579.

6. Megeji. N.W., Kumar, J.K., Singh, V., Kaul, V. K., Ahuja, P. S. (2005): Introducing Stevia rebaudiana, a natural zero-calorie sweetener, Curr Sci, 88(5) 801-805.

7. Strauss, S. (1995): The perfect sweetener? Technol Rev, 9818 - 20.

8. Ken, Y., Susumu, K., and Shujiro,S., (2002): Inhibitory effect of stevioside on tumor promotion by 12Otetradecanoylphorbol-13-acetate in two-stage carcinogenesis in mouse skin,Biol Pharm Bull, 24 (11) 1488-1490.

9. Nakamura, S., and Tamura, Y. (1985): Variation in the main glycosides of Stevia (Stevia rebaudiana Bertoni), Japanese Journal of Tropical Agriculture.

10. Sakaguchi, M., and Kan, T. (1982): As pesquisas japonesas com (Stevia rebaudiana (Bert.) Bertoni eo esteviosideo: Japanese researches on (Stevia rebaudiana (Bert.) Bertoni and stevioside.), Cienc Cult, 34 (2) 235-248.

11. Nower, A. A. (2014): "In vitro propagation and synthetic seeds production: An efficient methods for Stevia rebaudiana Bertoni, Sugar Tech, 16 (1) 100 - 108.

12. Ahmed, M. B., Salahin, M., Karim, R., Razvy, M. A., Hannan, M. M., Sultana, R., Hossain, M., Islam, R. (2007): An Efficient Method for in vitroClonal Propagation of a Newly Introduced Sweetener Plant (Stevia rebaudiana Bertoni.) in Bangladesh,American-Eurasian Journal of Scientific Research,2 (2) 121-125.

13. Hossain, M. A., Shamim, Kabir, A. H. M., Jahan, T. A., and Hasan, M. N. (2008): Micropopagation of Stevia, Int J SustainCrop Prod, 3(4) 1-9.

14. Mohamed, R. A., and Alhady, A. (2011): Micropropagation of Stevia rebaudiana Bertoni: A New Sweetening Crop in Egypt, Global Journal of Biotechnology \& Biochemistry, 6(4) 178-182.

15. Das, A., Saikat, G., and Nirmal, M. (2011): Micropropagation of an elite medicinal plant: Stevia rebaudiana (Bert), International Journal of Agricultural Research, 6 (1) 40 - 48.

16. Kalpana, M., Anbazhagan, M., Natarajan, V., and Dhanave, D. (2010): Improved micropropagation method for the enhancement of biomass in Stevia rebaudiana (Bert), Recent Research in Science and Technology, 2(1) $008-013$. 